\title{
IX. Von der geteilten Kontrolle zur kontrollierten Teilung
}

\section{Wiederbelebung des Kontrollrats? März bis August 1948}

Sokolowski war der Auszug aus dem Kontrollrat nach britischem Eindruck nicht leicht gefallen. Die Vertreter der Westmächte blieben konsterniert zurück und beschlossen auf Vorschlag Clays, zwei bis drei Tage abzuwarten, in der Hoffnung, zwischenzeitlich aus dem Verhalten der Sowjetunion im Koordinationskomitee entnehmen zu können, ob Sokolowskis Schritt das Ende des Kontrollrats bedeutete oder „ob es nur als eine erste Demonstration gemeint war" städten waren die zuständigen Instanzen gleichermaßen ratlos. In Washington wurde vermutet, hinter diesem „ersten Schritt" stehe langfristig das Ziel, die Arbeit des Kontrollrats zu beenden „und möglicherweise die westlichen Alliierten aus Berlin herauszuzwingen“2. In London rätselte man, ob es sich um den Auftakt zu einem „Nervenkrieg" handelte; noch seien keine Türen zugeschlagen. Robertson gab sich überzeugt, daß die Sowjets „den Kontrollapparat beibehalten wollen, bis die Zeit für eine Entscheidung über die Finanzreform kommt, und daß sie, wenn sie keine Einigung in dieser Frage bekommen, diesen endgültig beenden werden“. Der sowjetische Wunsch, die bereits anberaumten Sitzungen der diversen Kontrollratsgremien zu vertagen, sei vor allem ein Versuch, Zeit zu gewinnen, um in Moskau neue Instruktionen einzuholen $^{3}$. Die Franzosen sahen angesichts der „nervösen“ Atmosphäre in Berlin und der wechselseitigen scharfen Vorwürfe in der Presse wenig Chancen für eine Wiederaufnahme der Kontrollratstätigkeit, hofften aber zugleich, daß Sokolowski nicht seinen Rückzug aus dem Kontrollrat erklärt, sondern „nur“ die Sitzung vertagt habe, ohne eine neue Zusammenkunft anzusetzen. Saint-Hardouin hielt es für wahrscheinlich, daß die Sowjets die Deutschlandfrage auf diesem Wege auf die Regierungsebene zu heben versuchten, und riet zum Abwarten ${ }^{4}$.

In den nächsten Tagen bestätigte sich, daß die Sowjets noch keineswegs den endgültigen Bruch vollzogen hatten, sondern in der Tat auf Zeit spielten. Möglicherweise hatten sie den Monat ihres Vorsitzes gewählt, um ihrerseits den Kontrollrat sine die vertagen zu können, in der Hoffnung, die Westmächte zu unvorsichtigem, einseitigem

1 PRO, FO 1049/1392 (20.3. 1948). AMAE, Y 302, Bl. 26-45 (Stenogramm der Sitzung vom 20. 3. 1948).

2 NA, RG 59/Executive Secretariat (Acheson), box 17 (Background material for Secretary's press conference, 23. 3. 1948). Clay behauptete, „er wisse aus einer zuverlässigen Quelle mit Gewißheit von sowjetischen Truppenbewegungen auf der Achse Leipzig-Erfurt-Frankfurt“. Koenig distanzierte sich davon, empfahl aber seiner Regierung, vorsichtshalber eine "véritable“ Besatzungsarmee in Deutschland aufzubauen, „capable de tenir honorablement sa place dans un conflit éventuel“, und Gespräche mit den westlichen Alliierten aufzunehmen. AN, 457 (Bidault) AP 18 (21.3. 1948).

3 AMAE, Y 457 (Botschaft London, 22. 3. 1948). PRO, FO 1049/1392 (CCG, 22. 3. 1948).

4 AMAE, Y 301, Bl. 191 ff. (20. 3. 1948). 
Handeln provozieren und die Verantwortung auf sie abwälzen zu können. Sie hielten Kontakt zu den Westmächten über das Alliierte Sekretariat, das seine Arbeit in „normaler" Form und ungezwungener Atmosphäre erledigte. Daß Sokolowski eher spontan reagiert hatte und ein interner Beratungsbedarf bestand, schien sich zu bestätigen, als die Sowjets am 22. März ihre Kollegen um die „Verschiebung“ der Sitzung des Koordinationskomitees baten, die für den 23. März angesetzt war. Sie könnten kein neues Datum vorschlagen, hofften aber, so bestätigte Dratwin Äußerungen seines Repräsentanten im Alliierten Sekretariat, daß sie „demnächst“ stattfände. Nach kurzer Konsultation erklärten sich die Westmächte mit der „Vertagung“ einverstanden. Im Laufe der nächsten Stunden wurden die Sitzungen acht weiterer Gremien abgesagt, die für den 22. März anberaumt worden waren; begründet wurden die Absagen jedoch mit „konventionellen“ Entschuldigungen wie Krankheit, Überlastung oder vorübergehender Abwesenheit aus Berlin'.

Indem die Sowjets zu keiner klaren Linie kommen konnten oder wollten, war die Entscheidung den Westmächten zugeschoben. Robertson wiederholte seine Auffassung, daß die Sowjets den Kontrollrat ohnehin sprengen würden, wenn über die Währungsreform keine Einigung erzielt werde. „Die Verantwortung für den Bruch wäre dann nicht so klar, wie sie jetzt ist“, kamen taktische Überlegungen hinzu. Wenn mit einem baldigen Bruch gerechnet werden mußte, dann war die Gelegenheit günstig, indem man die dramatische Aktion Sokolowskis für Schuldzuweisungen nutzte. Robertsons Bedenken gegenüber Clays Vorschlag, daß die drei Westmächte im April unter seinem Vorsitz zusammentreten und die Sowjets zur Teilnahme einladen sollten, wurden vom Foreign Office geteilt: Damit übernähmen die Westmächte die Verantwortung für die Spaltung. Die drei westlichen Militärgouverneure beschlossen daher am 22. März auf Antrag Clays, keine Vertreter in die Gremien des Finanzdirektorats zu entsenden, ehe nicht die Grundsatzfragen im Kontrollrat diskutiert worden seien, d. h. ehe nicht die Sowjetunion einen demütigenden Rückzieher gemacht oder endgültig den Bruch vollzogen hatte. Am Abend des 22. März teilten Briten und Amerikaner ihrem sowjetischen Kollegen im Alliierten Sekretariat diesen Entschluß mit; die Franzosen schlossen sich offiziell erst zwei Tage später $a^{6}$.

Die Sowjets nutzten diese Auskunft, um den Westmächten die Schuld an der Klimaverschlechterung anzulasten. Zwar sagten sie am 23. März weitere Sitzungen, die für den 24. und 25. März angesetzt waren, telefonisch ab, und ein Treffen, das am Morgen noch bestätigt worden war, wurde am Nachmittag gleichfalls zurückgezogen. Zugleich betonten sie jedoch ihre Entschlossenheit, am 24. März die diversen Komitees des Finanzdirektorats tagen zu lassen. Alle Gremien, in denen die Währungsreform „informell“ weiter beraten wurde, sollten nach dem Willen der Sowjets am 24. März zusammentreten; solange die Währungsreform „zur Diskussion“ stehe, so ihre Begründung, werde das Finanzdirektorat tagen. Doch lehnten die Westmächte ihre Teilnahme an den Sitzungen der Komitees im Finanzdirektorat am 24. März gemäß ihrer Vereinbarung anderthalb Stunden vor Sitzungsbeginn $a^{7}$. Als die anglo-

5 NA, RG 59, 740.00119 Control(Germany)/3-2248 und /3-2348. AMAE, Y 302, Bl. 17, 20; Y 457 (No. 664 und 1276, 22. 3. 1948); Y 333, Bl. 124.

${ }^{6}$ PRO, FO 1049/1289 (22. und 24. 3. 1948). NA, RG 59, 740.00119 Control (Germany)/3-23.48. AMAE, Y 333, Bl. $166 \mathrm{f}$.

7 Tägliche Rundschau, 18. 4. 1948. 
amerikanischen Vertreter im Alliierten Sekretariat am 25. März von ihrem sowjetischen Kollegen zu erfahren suchten, ob die Sowjetunion am 30. März den Kontrollrat einzuberufen gedenke, wich dieser aus und verlangte ein vorbereitendes Treffen des Koordinationskomitees, um eine Tagesordnung zu erstellen. Das entsprach der Geschäftsordnung, doch konnte der britische Vertreter mit gutem Recht erwidern, die Tagesordnung der letzten Sitzung sei noch nicht erschöpft ${ }^{8}$. Am nächsten Tag hatten die Briten ihre schroffe Haltung abgeschwächt. Obwohl sie ihre prinzipielle Weigerung aufrechterhielten, vor Klärung der Grundsatzfragen an irgendwelchen Sitzungen teilzunehmen, stimmten sie einer „,außerordentlichen“ Zusammenkunft des Koordinationskomitees zu, um ausschließlich über die Tagesordnung für den Kontrollrat zu beraten. Die Franzosen gaben sich weniger „dogmatisch“ und erklärten sich bereit, auch an einer „normalen“ Sitzung des Koordinationskomitees teilzunehmen. Die USA blieben „unverbindlich“, weigerten sich aber wie die Briten, die Initiative für eine solche Zusammenkunft zu ergreifen, da die Sowjets „von dem üblichen Vorgehen“ abgewichen seien. Obwohl die Sowjets ein „außerordentliches“ Treffen gefordert hatten, gab ihr Vertreter keine weiteren Erklärungen ab und vertagte das Alliierte Sekretariat auf den 30. März; er hatte offenbar nur sondieren wollen. Das war für die Briten das Signal, daß es keine Sitzung des Kontrollrats mehr geben würde. Es war zugleich deutlich geworden, daß weder sie noch die Amerikaner beabsichtigten, durch Beantragung eines „außerordentlichen“ Treffens den Kontrollrat wiederzubeleben?. Nach Murphys Bericht „verbarg die sowjetische Delegation kaum ihre Bereitschaft, daß der Kontrollrat wieder zusammentreten sollte“, wollte aber „aus Prestigegründen“ nicht selbst die Initiative ergreifen, indem sie für den 30. März eine Sitzung einberief. Ihm waren die Gründe für das sowjetische Verhalten am 20. März noch immer „obskur“; er war aber überzeugt, „daß die Sowjets hofften, durch ihre Geste die Entwicklung in Westdeutschland zu verzögern, wenn nicht zu stoppen “10.

Wenn die Sowjetunion tatsächlich am Weiterbestehen des Kontrollrats interessiert war, dann hatte sie sich in eine fast ausweglose Situation manövriert, aus der die Westmächte sie nicht mehr herausließen. Daß die Entwicklung nicht nach Wunsch verlief, war aus den Verlautbarungen der SMAD abzulesen. Unter der Überschrift „Westmächte zerstören den Kontrollrat" erhob am 21. März die Tägliche Rundschau den Vorwurf, diese hätten „die Beschlüsse über den Kontrollmechanismus in Deutschland samt und sonders ungeniert über den Haufen“ geworfen, so daß der Kontrollrat „faktisch nicht mehr besteht“. Am 26. März brachte das Blatt auf der Titelseite ein Interview mit dem Stabschef der SMAD, Generalleutnant Lukjantschenko, der die Verletzung des Potsdamer Abkommens in den Vordergrund rückte; infolge ihrer gezielten Unterminierung des Kontrollrats liege „die volle Verantwortung“ für dessen Scheitern bei den Westmächten. Er vermied es jedoch peinlichst, vom Ende des Kontrollrats zu sprechen. Die Sowjetunion werde ihren Kampf für die Verwirklichung des Potsdamer Abkommens fortsetzen; „deshalb ist man sowjetischerseits für die Erhaltung eines solchen Kontrollrats.“ Aber, so beschrieb er die aktuelle Situation: „Wir können das fiktive Bestehen des Kontrollrats nicht unterstützen“, damit sowohl die faktische politische Handlungsunfähigkeit vor dem 20. März wie den ungeklärten Schwebezustand

8 AMAE, Y 457 (No. 711-712, 25.3. 1948). AN, 457 (Bidault) AP 67/I (GFCC, 25. 3. 1948).

9 PRO, FO 1049/1289 (R.G.Raw/ASEC, 26.3. 1948).

10 NA, RG 59, 740.00119 Control(Germany)/3-2748. 
seitdem meinend. Abschließend bot Lukjantschenko den Ausweg aus der gegenwärtigen Sackgasse an: Die Sitzung des Koordinationskomitees vom 23. März sei lediglich „aus technischen Gründen“ abgesagt worden. Jedoch nur zwei Tage später, am 28. März, an dem Tag, an dem die Behinderungen im Berlinverkehr angeordnet wurden, folgte in einem Kommentar der Hinweis, daß die Sowjetunion sich entschieden hatte und keine weitere Initiative ergreifen würde: $\mathrm{Da}$ sie es nicht verantworten könne, mit dem Kontrollrat den Westmächten einen „Deckmantel ihrer Separat- und Spaltungspolitik, als Mittel zur Tarnung, als Fiktion" zu belassen, sei der Auszug am 20. März gerechtfertigt gewesen. „Somit hängt es von den Westmächten ab, ob der Kontrollrat weiterbestehen wird oder nicht." ${ }^{\prime \prime}$

Auch die waren unsicher hinsichtlich ihres weiteren Vorgehens. Einerseits glaubten Clay und Robertson, der Kontrollrat werde nicht mehr zusammentreten, und wenn, dann nur noch, um festzustellen, daß er keine Daseinsberechtigung mehr habe. Andererseits war die Verweigerung einer Sitzung ein schwerwiegender Schritt, der der politischen Absicherung bedurfte. Nachdem die Sowjets den 30. März als regulären Sitzungstag des Kontrollrats ohne eine neue Initiative hatten verstreichen lassen, trafen sich Clay, Koenig und Robertson, um ihr weiteres Vorgehen zu beraten. Robertson empfahl, von der Unausweichlichkeit des Bruchs überzeugt, Clay, dem turnusgemäß der Vorsitz zugefallen wäre, solle zum 10. April eine Sitzung einberufen: Kamen die Sowjets nicht, so war die Schuldfrage geklärt; kamen sie doch, dann zweifellos nur, um die alten Vorwürfe neu vorzubringen; verweigerte die Sowjetunion eine Änderung ihrer Politik, vor allem die Beendigung ihrer Blockade gesamtdeutscher Regelungen, sollten die Westmächte die Sitzung sine die vertagen. Allerdings wollte Robertson, der für diese Linie die Unterstützung des Foreign Office fand, dabei jede „Erklärung oder Eingeständnis, daß der Kontrollrat tot ist“, vermeiden ${ }^{12}$. Der Entscheidungsdruck wuchs, als die Sowjets am 1. April, dem ersten Tag des amerikanischen Vorsitzes in den Kontrollratsgremien, ihre „Baby-Blockade“ begannen und die Prawda schrieb: „Die Teilung Deutschlands ist eine vollendete Tatsache geworden. ${ }^{\text {" }}{ }^{13}$ Angesichts der beginnenden Berlin-Blockade schien auch Koenig ein sowjetischer „Plan“ abzurollen, der nicht mehr zu stoppen war. Dieser Eindruck wurde dadurch verstärkt, daß die sowjetische Kontrollratsdelegation am 1. April auch die gesellschaftlichen Kontakte abbrach, als sie (wie die jugoslawische, aber noch nicht die polnische und die tschechische Militärmission) zu einem Empfang des britischen Protokollchefs des Alliierten Sekretariats nicht erschien ${ }^{14}$. Daß die Briten in dieser Situation von Clay eine Sitzung des Kontrollrats verlangten, um die Behinderungen im Berlinverkehr zu diskutieren, mochte das Ziel der Nadelstiche gewesen sein. Auch bei OMGUS gab es Befürworter eines derartigen Vorgehens; doch Clay hatte wenig Interesse an einer Wiederbelebung des Kontrollrats.

11 Tägliche Rundschau, 21., 26. und 28. 3. 1948. Nach Saint-Hardouins Eindruck hatte die sowjetisch kontrollierte Presse sich von Beginn an bemüh,, ,à des degrés divers, de présenter comme définitive cette rupture"; gleichwohl seien Ungereimtheiten zu beobachten gewesen. AMAE, Y 333, Bl. $166 \mathrm{ff}$.

12 PRO, FO 1049/1289 (30.3. 1948).

13 Nach sowjetischen Angaben begannen die Behinderungen im Berlin-Verkehr am 28. 3. 1948. AMAE, Y 207, Bl. $113 \mathrm{ff} ., 146$. Offiziell angekündigt wurden sie am 30. 3.

14 NA, RG 59, 740.00119 Control(Germany)/4-148 und /4-248; RG 59/Bohlen, box 9, folder: Top Secret File (Retaliatory Action in Germany, 2. 4. 1948). CP, S. 607. AMAE, Y 333, Bl. 148 f.; Y 457 (No. 806-809, 2. 4. 1948). 
Gleichwohl ließen die Franzosen nichts unversucht, Clay zu einer Einberufung des Kontrollrats zu bewegen. Mit Unbehagen erinnerten sie sich daran, daß Clay den 10. April als letzten Termin für eine Einigung in der Währungsreformfrage gesetzt und sich für den Fall anhaltenden Dissenses freie Hand vorbehalten hatte. Sie wollten Klarheit, ehe sie sich auf der Londoner Sechs-Mächte-Konferenz endgültig auf einen Weststaat festlegten, deren zweite und entscheidende Phase am 20. April begann. Sollten die Sowjets eine Sitzung des Kontrollrats zu neuen verbalen Attacken nutzen, sei dieser „endgültig gestorben“, während er nach der bisherigen Auffassung theoretisch nur „ruhte“, solange er nicht zusammentrat, vor allem da der sowjetische Vertreter im Alliierten Sekretariat weiter mitarbeitete und Briefe im Namen des Kontrollrats expedierte. Die Franzosen schlugen daher vor, nicht nur die Ereignisse des 20. März, sondern auch ein „technisches“ Problem auf die Tagesordnung zu setzen, um den Sowjets einen zusätzlichen Anreiz zum Kommen zu bieten, und sie erklärten sich bereit, bei Sokolowski „informell“" zu sondieren ${ }^{15}$. Auch Robertson drängte Clay am 6. April, eine Sitzung des Kontrollrats sowie eine vorbereitende Zusammenkunft des Koordinationskomitees einzuberufen ${ }^{16}$. Nach den ersten Meldungen Clays über Beeinträchtigungen des Berlin-Verkehrs hatten State und War Department ebenfalls die Möglichkeit ventiliert, daß „nach Konsultation mit den Briten und Franzosen, er [Clay] ein Treffen des Kontrollrats einberuft als ernsthaften Ausdruck unseres guten Glaubens und als Zeichen unseres ernsthaften Willens, ein Scheitern des Kontrollrats als des obersten deutschen Regierungsorgans zu vermeiden“; alternativ könne ein ähnlicher Vorstoß auf diplomatischer Ebene in Moskau unternommen werden ${ }^{17}$.

Doch Clay hatte sich bereits am 4. April entschieden: Er werde nur einberufen, wenn einer seiner Kollegen ihn dazu offiziell auffordere. „Sein Hauptgrund dafür sei, daß er glaube, daß wir niemals einen Bruch unter günstigeren Umständen bekommen werden als jetzt." Als Robertson dennoch drängte, erklärte Clay sich zu einem letzten Angebot bereit. Er werde allen Kollegen schriftlich mitteilen, „da ihm keine Fragen zur Aufnahme in die Tagesordnung vorgelegt worden seien, schlage er nicht vor, ein Treffen für den 10. April einzuberufen, werde ein solches aber jederzeit einberufen, wenn er Vorschläge seiner Kollegen erhalte“. Robertson stimmte sofort zu: „Es belegt seine Bereitschaft, den Kontrollrat tagen zu lassen, und es hält die Fiktion aufrecht, daß der Kontrollrat noch besteht." Privatim gaben er und Koenig, der sich am 8. April anschloß, jedoch zu verstehen, daß sie den Kontrollrat für „erledigt“ erachteten. Robertson empfahl daher seiner Regierung, keine Sitzung zu beantragen, sondern es den Sowjets zu überlassen, „ein Treffen vorzuschlagen oder auch nicht“. Der Kontrollrat, so schloß sich Murphy am 13. April an, sei „gestorben“, dürfe aber als „Wahrzeichen der deutschen Einheit“ seitens des Westens nicht offiziell in Frage gestellt werden. „Es wäre vorzuziehen, die Last für seine Auflösung auf der Sowjetunion ruhen zu lassen. " ${ }^{18}$ Als die New York Times die amerikanische Haltung dahingehend charakterisierte, „daß die USA sich entschieden haben, nicht auf die Wiederaufnahme des Kontrollrats zu drängen, und zu dem Entschluß gekommen sind, mit der baldmöglichen

15 AMAE, Y 333, Bl. 158.

16 PRO, FO 1049/1289.

17 NA, RG 59/Bohlen, box 8, folder: Top Secret File (6. 5. 1948).

18 NA, RG 59, 740.00119 Control(Germany)/4-848. AN, 457 (Bidault) AP 67/I (GFCC, 4. 4. 1948). AMAE, Y 457 (No. 847, 5. 4. 1948). FRUS, 1948/II, S. 885, 892 ff. 
Einsetzung einer westdeutschen Regierung fortzufahren“, dementierte das State Department den Inhalt der Meldung nicht, sondern bedauerte lediglich den Bericht als „unzeitig"19.

Die SMAD antwortete, wie sich zunehmend einbürgerte, ihrerseits durch eine Presseerklärung. Darin wandte sie sich gegen Meldungen westlicher Zeitungen, Clay habe zum 10. April keine Sitzung des Kontrollrats einberufen, weil auf sowjetischer Seite kein Interesse mehr an einer Erörterung der Währungsreformfrage bestehe. Sie habe vielmehr trotz der Ereignisse des 20. März angeboten, „die Arbeit der Komitees und des Finanzdirektorats, die mit der Vorbereitung einer gesamtdeutschen Währungsreform im Zusammenhang steht, fortzusetzen, um diese in der vom Kontrollrat festgesetzten Frist [10. April] abzuschließen“, zumal in weiten Bereichen längst Einigung erzielt worden sei. Die Ablehnung der Westmächte beweise, daß sie nur einen Vorwand suchten, um ihre Währungsreform in den Westzonen als „Separataktion“ durchzuführen, die „zur Zerstörung des deutschen Staates und zum wirtschaftlichen Chaos in Deutschland“ führen müsse ${ }^{20}$. Der Hinweis, daß nicht der 20. März, sondern der 10. April das entscheidende Datum sei, sollte die sowjetische Kooperationsbereitschaft dem westlichen Ultimatum gegenüberstellen, die Verantwortung dem Westen zuschieben, der die Einigung im Kontrollrat fürchte, weil sie seine Pläne durchkreuze. Das war nicht falsch, verwechselte aber Ursache und Anlaß, ohne den taktischen Fehler korrigieren zu können, daß Sokolowski, nicht Clay den Kontrollrat sine die vertagt hatte. Die Franzosen vermuteten, Moskau habe Sokolowski „Vorhaltungen“ gemacht; „eine gewisse sowjetische Zurückhaltung zeuge ohne Zweifel von dem Bedauern, zu schnell vorangegangen zu sein. ${ }^{.21}$ War diese Meldung ein Kompromißangebot oder nur Propaganda? Die Westmächte entschieden sich für das letztere ${ }^{22}$.

Als der 10. April ohne Sitzung verstrich, waren die Fronten geklärt, nachdem keine der Mächte (nicht zuletzt aus Prestigegründen) die Einberufung des Kontrollrats verlangt hatte. Es schien im Gegenteil eine gewisse „Atmosphäre der Entspannung“ einzukehren. Die Arbeit des Kontrollrats kam jetzt auch auf informeller Ebene praktisch zum Erliegen. Gleichwohl erschienen alle Delegationen weiterhin vollständig im Büro. Allein mit dem Ordnen der Akten war das Personal auf Wochen beschäftigt, auch wenn es die Gelegenheit nutzte, zwischendurch Tennis oder Baseball zu spielen. Allerdings wurden - sinnbildlich für die wachsende Sprachlosigkeit zwischen den Alliierten - Entlassungen bei den russischen Übersetzern gemeldet. Die Westmächte werteten das als Indiz dafür, daß die Sowjets nicht mehr mit einer Wiederbelebung rechneten. Zwar widerrief Clay am 28. Mai eine Anweisung des Control Office, die amerikanischen Mitglieder schrittweise bis Ende September aus dem Alliierten Sekretariat zurückzuziehen, und gestattete nur, maximal ein Drittel des Personals bis Ende Juli abzubauen, doch das war eine rein taktische Vorsichtsmaßnahme. Er war nicht bereit, die letzten Brücken einseitig abzubrechen, akzeptierte aber den sowjetischen

\footnotetext{
19 NA, RG 59/Executive Secretariat (Acheson), box 17 (Background material for Secretary's press conference, 14. 4. 1948).

20 Tägliche Rundschau, 14. 4. 1948.

21 AMAE, Y 333, Bl. 187 (22. 4. 1948).

22 AMAE, Eu(1944-60)Allemagne/92, Bl. 56 ff. (11. und 14. 4. 1948).
} 
Wunsch, die Zahl der Unterorgane der Berliner Kommandantur wegen „Personalmangels" zu reduzieren ${ }^{23}$.

Die Westmächte interpretierten den Schwebezustand eher als Ruhe vor dem Sturm, entschlossen, sich von den Sowjets nicht aus Berlin verdrängen zu lassen ${ }^{24}$. Für entsprechende Befürchtungen gab die rapide Verschlechterung der Lage in der Kommandantur Anlaß, deren Sitzungen zur „Farce“ verkamen. Nach amerikanischem Eindruck waren die Sowjets bestrebt, durch nervenzehrende Debatten über Verfahrensfragen, durch bewußte Beleidigungen und Unhöflichkeiten die Westmächte zum Bruch über belanglose Fragen zu provozieren, um diesen eine ähnliche Niederlage zu bereiten, wie sie selbst im Kontrollrat erlitten hatten. Anfang Mai schien der „endgültige Bruch" unmittelbar bevorzustehen, als die Sowjets in den Westsektoren durch ihre Hilfstruppen in SED und FDGB chaotische Zustände herbeizuführen suchten ${ }^{25}$. Zur gleichen Zeit forderte Tjulpanow die SED-Führung auf, nach volksdemokratischem Beispiel Kurs auf die Schaffung eines Ostzonenstaates zu nehmen; „faktisch ist eine Aufteilung Deutschlands in zwei Teile [...] zustande gekommen." ${ }^{26}$ Während die SMAD um den 20. Mai die Vorbereitungen zur einseitigen Währungsreform in der SBZ abschloß, legte zur gleichen Zeit die sowjetische Kontrollratsdelegation „erhebliche Aktivitäten" an den Tag, die noch einmal ein Angebot an die Westmächte zu sein schienen. Sie forderte beim OMGUS fehlende Papiere für das Wirtschaftsdirektorat an, bat um die sofortige Übermittlung des amerikanischen Export-Import-Plans von 1946 und legte selbst eigene Schriftstücke vor. Zudem wurden verschiedene OMGUS-Vertreter von ihren sowjetischen Kollegen zum Essen in deren Privatquartier eingeladen ${ }^{27}$.

Die USA rätselten über die Motive dieser Initiative. Im Grunde widersprach der definitive Rückzug aus dem Kontrollrat den Interessen der Sowjetunion: Mit dem Kontrollrat verlor sie das letzte Instrument, mit dessen Hilfe sie überhaupt noch Einfluß auf die Entwicklung in den Westzonen hätte nehmen können. Sein Ende mußte dort die Bereitschaft der Deutschen zur Gründung eines Teilstaates noch verstärken. Wenn die Sowjetunion den Bruch zu verantworten hatte, war ihrer Einheits- bzw. Wiedervereinigungspropaganda der Boden entzogen. „Eine sowjetische Entscheidung, das Ende des Kontrollrats herbeizuführen, wäre das Eingeständnis einer sowjetischen Niederlage, da sie die Anerkennung Moskaus widerspiegeln würde, keine auch nur begrenzte Teilhabe an den Angelegenheiten Westdeutschlands zu erreichen, und es würde das Eingeständnis enthalten, zur Zusammenarbeit mit anderen Großmächten unfähig zu sein." Solange der Kontrollrat noch formal bestand, blieb der Sowjetunion die Möglichkeit, sich von der beginnenden Kraftprobe um Berlin zurückzuziehen und durch „eine dramatische diplomatische Geste [...] eine begrenzte Wiederbelebung des Kontrollapparats herbeizuführen, entweder in seiner bisherigen oder in einer anderen

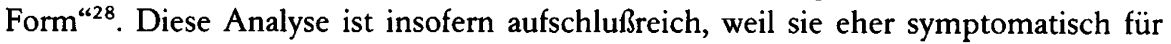
die amerikanische Entscheidungsfindung als für die sowjetische zu sein scheint, indem sie spiegelbildlich die Vor- und Nachteile, die Ambivalenzen der westlichen Poli-

23 NA, RG 260/CAD, box 81 (Staff Conference, 22. 5. 1948). Vgl. oben S. 63.

${ }_{24} \mathrm{PRO}, \mathrm{FO} 800 / 467 / \mathrm{Ger} / 48 / 16$ und 17 (Bevin, 29. 4. und 5. 5. 1948).

25 NA, RG 59, 740.00119 Control(Germany)/4-2948, /5-848 und /5-2048.

26 Badstübner/Loth, Pieck, S. 216 (8. 5. 1948).

27 NA, RG 260/CAD, box 81 (Staff Conference, 22. 5. 1948).

28 NA, RG 59/Bohlen, box 8, folder: Top Secret File (6. 5. 1948). 
tik reflektierte. Denn auch die USA hatten sich gegen eine Fortsetzung der Tätigkeit des Kontrollrats entschieden, da er sich als ineffektiv erwiesen hatte und seine Wiederbelebung ihren deutschlandpolitischen Zielen widersprach. Sie hatten aber an seinem formellen Ende kein Interesse, gerade weil er das Symbol der Nachkriegskooperation war, weil er Kommunikationskanäle zu den Sowjets offenhielt, gewisse Einblicke in die SBZ eröffnete und die westlichen Vorbehaltsrechte in Berlin und für Gesamtdeutschland begründete ${ }^{29}$. Doch die eine wie die andere Seite hatte sich soweit vorgewagt, daß die Logik der Sachzwänge wie des nationalen Prestiges keine Umkehr mehr zuließ.

Dagegen kam die Zuspitzung der Krise in Berlin den Franzosen nicht völlig unwillkommen. Mit Erstaunen registrierten sie, wie unbegründet ihre bisherigen Befürchtungen schienen, die Deutschen seien derart auf die nationale Einheit fixiert, daß der Westen gezwungen sein werde, mit der Sowjetunion um die Gunst der Deutschen zu konkurrieren. Statt dessen häuften sich die Anzeichen, daß die Mehrheit der Westdeutschen bereit war, die Einheit der Freiheit zu opfern, vor allem wenn die Sowjetunion, die sich als Vertreter der nationalen Interessen gerierte, sich durch ihre Politik in Berlin selbst desavouierte ${ }^{30}$. Einerseits lag den Franzosen daran, den Sowjets die Verantwortung für eine Teilung zuzuschieben, die sie, wenn der Kontrollrat endgültig scheiterte, unter nationalen Sicherheitsinteressen nur begrüßen konnten. Andererseits rechneten sie aber im Gegensatz zu den USA, die im Falle einer separaten Währungsreform in den Westzonen nur Drohgebärden seitens der Sowjets erwarteten, mit weitergehenden Maßnahmen, ja mit einer „Art Blockade“"31. Sie forderten daher die Verschiebung der Währungsreform in den Westzonen um einen Monat. Nicht zuletzt aus innenpolitischen Gründen wollten sie im Juni, wenn sie turnusgemäß den Vorsitz im Kontrollrat übernahmen, einen neuen Vorstoß zur Einberufung des Kontrollrats unternehmen, obwohl (oder weil?) sie in London der Bildung eines westdeutschen Staates zustimmten. Zwar war ihnen ein in Zonen geteiltes Deutschland noch immer sympathischer, denn gerade ein schwacher und handlungsunfähiger Kontrollrat garantierte ihnen ein Maximum an zonaler Autonomie und einen durch das Veto steuerbaren Einfluß in ganz Deutschland, soweit und solange ihnen das erforderlich schien. Aber unter den sich abzeichnenden Bedingungen wurde die Teilung Deutschlands zu einer immer positiver beurteilten Alternative.

Während Clay und Robertson bislang im Sinne der ursprünglichen Verabredung jeweils nur nachträglich offiziell festgestellt hatten, daß keine Delegation Tagesordnungspunkte vorgeschlagen habe, die eine Einberufung des Kontrollrats gerechtfertigt

29 Kennan vertrat im Hinblick auf mögliche Verhandlungen mit den Sowjets die Auffassung, „for various reasons certain powers of control will have to be retained by the four allied governments, and allied control council must exist for this purpose. However, these controls would be kept at a minimum, and every effort made to reduce the scope for individual veto. The controls would relate principally to disarmament, reparations, the Ruhr, and the treatment of displaced persons." NA, RG 59/ Bohlen, box 4, folder: Memos, July-Dec. 48 (Kennan an Marshall, 18. 8. 1948).

30 AMAE, Eu(1944-60)Allemagne/82, Bl. 340 ff. (MAE, Sous-Direction d'Europe Centrale, 11.5. 1948).

31 AMAE, Eu(1944-60)Allemagne/92, Bl. 69 f. (Leroy-Beaulieu/Seydoux, 21. 5. 1948), 74 (MAE, Direction Générale des Affaires Politiques, 24. 5. 1948). Robertson hatte mit Pressionen, aber nicht mit einer Totalblockade gerechnet. PRO, FO 371/70504/C6057 (20. 7. 1948). Amerikanische Geheimdienstberichte sagten die Totalblockade und ihre Begründung (Absperrung des Geldüberhangs) voraus, doch mehr als eine flexible Bluff-Politik der Sowjetunion wurde nicht erwartet. BA, Z 45 F/ OMGUS, FINAD/2/103-1 (8. 5. 1948). 
hätten, drängten die Franzosen ihre Kollegen zu einer ausdrücklichen Entscheidung, indem sie am 4. Juni im Alliierten Sekretariat anboten, sie würden eine Sitzung einberufen, wenn eine Macht das verlange. Der sowjetische Vertreter nahm das Angebot, auf das Antwort bis zum 6. Juni erbeten wurde, schweigend zur Kenntnis. Während die USA und Großbritannien ${ }^{32}$ am 6. Juni ihr Desinteresse mitteilten, bat Sokolowski um Bedenkzeit bis zum nächsten Tag. Nach neuerlicher Bitte um Aufschub überreichten die Sowjets am Abend des 8. Juni ihre negative Antwort. Unter Hinweis auf die Äußerungen von Lukjantschenko und Dratwin in der Täglichen Rundschau betonte Sokolowski darin erneut, daß „sowjetischerseits [...] der Kontrollrat in jeder Weise unterstützt [werde], sofern seine Tätigkeit auf den Beschlüssen der Potsdamer Konferenz beruhen wird“33. Nachdem Sokolowski am 20. März erklärt hatte, der Kontrollrat habe „faktisch“ aufgehört zu bestehen, versuchten die Sowjets nun den Eindruck zu verwischen, sie hätten das Kontrollratsabkommen aufgekündigt; sie schlossen sich der westlichen Rechtsfiktion an, daß der Kontrollrat weiterbestehe, aber ansonsten „ruhe“"34. Insgesamt schien die Sowjetunion nur an einer propagandistischen Korrektur der Schuldfrage interessiert zu sein. Nachdem Koenig festgestellt hatte, er werde keine Sitzung einberufen, beschuldigte sie die Westmächte, sie hätten die sowjetische Antwort nicht abgewartet und damit ihr mangelndes Interesse an der deutschen Einheit dokumentiert.

In der französischen Delegation hielt sich hartnäckig der Eindruck, die Sowjets wünschten eine Sitzung ${ }^{35}$. Noiret unternahm daher am 10. Juni einen neuen brieflichen Vorstoß, auch um zu verhindern, daß Frankreich die Schuld für das Scheitern der Vier-Mächte-Verwaltung angelastet werden konnte. Doch waren die Sowjets ebensowenig zu einer positiven Reaktion in der Lage oder willens wie die Angelsachsen, über deren Haltung Noiret am 11. Juni urteilte: „Ihre Entscheidung scheint gefallen.“ Die SMAD versuchte vielmehr, den Franzosen die Verantwortung zuzuschieben: Der jeweilige Vorsitzende sei für Einberufung und Tagesordnung verantwortlich. Zornig warf Clay den Franzosen „Appeasement“ und Verletzung der Absprachen vor ${ }^{36}$. Er befürchtete, mit ein wenig Geschick seien die Sowjets nun in der Lage, durch Zustimmung zu einem Treffen den USA und Großbritannien den Schwarzen Peter zuzuschieben und derart die einseitige Währungsreform in den Westzonen politisch unmöglich zu machen. Zudem hatte OMGUS bereits im April 1948 die Planungen für die Übergabe der Geschäfte an eine Alliierte Hohe Kommission der drei Westmächte in Angriff genommen ${ }^{37}$. Als Frankreich Anfang Juni 1948 versuchte, in einem Ab-

32 Das Foreign Office war zurückhaltend. Kam eine Sitzung zustande, sollte Robertson weder ablehnen noch Zugeständnisse machen. PRO, FO 1049/1289.

33 Tägliche Rundschau, 9.6. 1948.

34 Es war vermutlich kein Versprecher, wenn der sowjetische Vertreter in der Kommandantur am 19. 5. 1948 forderte, die neue Berliner Verfassung bedürfe der Zustimmung durch den Kontrollrat. NA, RG 59, 740.00119 Control(Germany)/5-2048.

35 AMAE, Y 457 (No. 1702, 1. 6.; No. 1154, 7.6.; No. 1164-1166, 9. 6.; No. 3017, 9. 6. 1948). Wie sein Kollege Seydoux hatte Murphy den Eindruck, daß die Sowjets eine Sitzung wünschten, wenn auch nur, um in einer öffentlichkeitswirksameren Form als am 20.3. ihre Vorwürfe zu wiederholen, aber aus Prestigegründen diese nicht beantragen wollten. NA, RG 59, 740.00119 Control(Germany)/ 6-948.

36 NA, RG 200/Clay, box 14 (10.6. 1948); RG 59, 740.00119 Control(Germany)/6-1048. CP, S. 673. Noiret verteidigte sich, Koenig habe ihn von der Absprache nicht informiert.

37 Rupieper, Der besetzte Verbündete, S. $41 \mathrm{f}$. 
kommen der Westmächte über neue Reparationsprozeduren den Vorbehalt aufzunehmen, dieses gelte nur für die Zeit, in der die Vier-Mächte-Organe ,jetzt, zumindest vorübergehend, außer Betrieb“ seien, bestand Clay auf Streichung der Passage, weil „diese dahingehend ausgelegt werden könnte, daß es eine Einladung sei, den VierMächte-Apparat wieder zusammenzusetzen“. Die USA drängten auf die rasche Verabschiedung der Vereinbarung noch im Juni, „weil am 1. Juli, nach ihrem Verständnis, die Sowjets den Vorsitz im Kontrollrat übernehmen, und sie könnten, wenn bis zu diesem Zeitpunkt durch die USA im Hinblick auf die Reparationen nichts unternommen worden ist, ein Treffen des [Kontroll-]Rats zu dem Zwecke einberufen, um u. a. über die Reparationen zu verhandeln“38.

Noch einmal kam überraschend Bewegung von unerwarteter Seite in die Frage, als am 16. Juni die polnische Militärmission eine Sitzung des Kontrollrats beantragte, um die „Londoner Empfehlungen“ der Sechs-Mächte-Konferenz zur Gründung eines westdeutschen Staates zu beraten. Hinter diesem Vorstoß vermutete Clay ein Manöver der Sowjetunion ${ }^{39}$, doch griff diese die Initiative im Alliierten Sekretariat nicht auf sei es aus Taktik, sei es aus Unsicherheit über den einzuschlagenden Weg. Jedenfalls spielte die SMAD weiter auf Zeit. Am 17. Juni war ihr Vertreter im Alliierten Sekretariat zu einer Beratung des polnischen Briefs nicht in der Lage, da er - trotz Veröffentlichung in der Täglichen Rundschau - „noch nicht übersetzt“ sei. Als der Brief am nächsten Tag erneut beraten werden sollte, war der sowjetische Vertreter wieder ohne Instruktionen. Die Vertreter der USA und Großbritanniens demonstrierten ihre Zurückhaltung, indem sie die Beantwortung des Briefes den Regierungen übertragen und damit dem Kontrollrat entziehen wollten. Unter vier Augen und auf hartnäckiges Befragen erklärte der sowjetische Vertreter seinem französischen Kollegen lediglich, Sokolowski sei bereit, an einer Sitzung des Kontrollrats teilzunehmen, wenn er dort eine Antwort auf seine Fragen vom 20. März erhalte. Das kam einer Absage gleich, nachdem die Sowjetunion am 16. Juni die Berliner Kommandantur verlassen hatte. Am 19. Juni erklärte sich der sowjetische Vertreter im Alliierten Sekretariat noch immer nicht imstande, die Haltung seiner Regierung zu dem polnischen Schreiben zu erläutern, vielleicht auch, um den westlichen Vertretern den Vortritt bei der Ablehnung zu überlassen. Gleichwohl sondierte der verunsicherte Noiret, bei Abwesenheit Koenigs und wiederum ohne Clay und Robertson vorher zu konsultieren, über das Alliierte Sekretariat am 19. Juni abermals bei den Sowjets, ob sie eine Sitzung am 21. Juni wünschten. Er selbst erklärte seine bzw. Koenigs Bereitschaft, jederzeit eine solche Zusammenkunft herbeizuführen. Mehr, so Noiret gegenüber Paris, könne er für „eine Wiederaufnahme vierseitigen Handelns" nicht tun, „ohne die Amerikaner und die Briten zu verletzen. Es kann dagegen nicht die Rede davon sein, daß wir eine Sitzung beantragen, denn Clay und Robertson haben mir bereits unmißverständlich ihre Meinung zu diesem Thema mitgeteilt“; nämlich daß sie, so Clay, „persönlich nicht bereit“ seien, an einer Sitzung teilzunehmen ${ }^{40}$.

38 FRUS, 1948/II, S. 756, 764, 768.

39 Clay schloß nicht aus, der Vorstoß könne „from elsewhere“ stammen, d. h. wohl von den Franzosen, die es auf diesem Umweg den vier Kontrollratsmitgliedern ersparen wollten, durch einen Antrag ihr Gesicht zu verlieren. CP, S. 684 .

40 AMAE, Y 457 (No. 3148, 16. 6.; No. 1220, 18. 6.; No. 3211, 19.6. 1948). AN, 457 (Bidault) AP 67/I (GFCC, 11.-19.6. 1948). 
Obwohl Briten und Amerikaner eine Sitzung des Kontrollrats in keinem Fall mehr wollten, Franzosen und Sowjets zumindest aus taktischen und Prestigegründen eine solche nicht mehr zu beantragen wagten, kam am 22. Juni zum letzten Mal ein VierMächte-Treffen zustande, als die jeweiligen Vertreter im Finanzdirektorat in einer inoffiziellen Sitzung über die Währungsreform in Berlin berieten ${ }^{41}$. Clay hatte das, ohne wohl ernsthaft an einen Erfolg zu glauben, den Sowjets brieflich vorgeschlagen. Die Franzosen hatten die Initiative aufgegriffen und kurzfristig die telefonische Zustimmung Sokolowskis zu dem Treffen herbeigeführt. Die Westmächte waren in unterschiedlichem Maße bereit, die Einbeziehung ganz Berlins in das Währungsgebiet der SBZ zu akzeptieren, wenn die Reform in der ehemaligen Hauptstadt unter der formalen Aufsicht der Kommandantur stattfand und ihre Rechte in Berlin „dem Schein nach" gewahrt blieben. Indigniert wiesen die Sowjets ein solches Ansinnen zurück und begründeten ihre Ablehnung damit, die Westmächte hätten das Vier-Mächte-Regime durch die separate Währungsreform in den Westzonen zerstört; daher sei allein die SMAD für Berlin zuständig ${ }^{42}$. Nach dem Scheitern dieser Gespräche sagten die Sowjets am 25. Juni die Teilnahme ihrer Vertreter in den Organen der Kommandantur ab, z.T. ohne Angabe von Gründen; andere Sitzungen wurden verschoben. Erst am 1. Juli, als die Sowjets wieder den Vorsitz in allen Organen übernahmen, teilte ihr Stabschef im Alliierten Sekretariat der Kommandantur seinen westlichen Kollegen in einer Sondersitzung mit, daß seine Delegation an keiner Sitzung der Kommandantur oder ihrer Unterorgane mehr teilnehmen werde, da diese ihre Tätigkeit „faktisch eingestellt" habe, daß sie aber die gemeinsamen Beschlüsse weiterhin als gültig ansehe. Zur Begründung führte er die Währungsreform an und den angeblichen Auszug des amerikanischen Stadtkommandanten Howley aus der Sitzung vom 16. Juni, der nach fruchtlosen und bitteren Debatten diese verlassen hatte, nachdem er seinem Stellvertreter die Geschäfte übertragen hatte ${ }^{43}$. Das war ein durchsichtiger Versuch, dies als Parallele zum Verhalten Sokolowskis am 20. März im Kontrollrat zu konstruieren.

Insgesamt sind die Motive und Ziele der sowjetischen Politik in dieser Situation schwer zu fassen. Wenn Moskau eine Blockade über Berlin verhängte, um seine Zone vor der Überschwemmung mit entwerteten Reichsmark zu verhindern, konnte es in diesem Punkt mit der stillschweigenden Billigung der Westmächte rechnen ${ }^{44}$. Während die Sowjetunion nach britischen Geheimdienstberichten überzeugt war, die Westmächte bis zum August aus Berlin vertreiben zu können ${ }^{45}$, so war der amerikanische Eindruck gerade entgegengesetzt. Botschafter Caffery berichtete aus kommunistischen Quellen in Paris, Moskau wolle die Rückkehr zur Vier-Mächte-Verwaltung erzwingen, plane jedoch keinen „entscheidenden Machtkampf“ bzw. die „Eroberung“ von Berlin: „Das Berliner Grundproblem scheint nicht die Währung, sondern die

41 Berlin. Quellen und Dokumente, S. $1431 \mathrm{ff}$. FRUS, 1948/II, S. $912 \mathrm{ff}$.

42 AMAE, Eu(1944-60)Allemagne/92, B1. 165, 198 (GFCC, 22. und 23. 3. 1948). FRUS, 1948/II, S. 903 (Clay, 2. 5. 1948). CP, S. 694, 699.

43 NA, RG 59, 740.00119 Control(Germany)/6-2648 und /7-648. FRUS, 1948/II, S. 908 f., 941. Tägliche Rundschau, 2. 7. 1948. Keiderling, Kommandantur, S. 607 ff.

44 Vgl. S. 297 mit Anm. 152. Die Blockade war am 1.4.1948 in der ostdeutschen Presse als Schutz Berlins gegen „Hungerflüchtlinge und Bandenüberfälle“ deklariert worden. Tjulpanow schob am 2. 5. als Begründung den Schutz Berlins vor "Ausplünderungen“ durch das westliche Kapital nach. Berlin, Behauptung, S. 445, 474.

45 PRO, FO 800/467/Ger/48/31 (28.6. 1948). Stalin bestritt am 3.8. 1948, Ziel der Blockade sei die Vertreibung der Westmächte aus Berlin. FRUS, 1948/II, S. 1000, 1004. 
Vier-Mächte-Herrschaft zu sein. ““6 Clay gewann frühzeitig den Eindruck, Ziel der Sowjets sei es, über Berlin zu verhandeln und eine Vier-Mächte-Außenministerkonferenz über Deutschland zu erzwingen ${ }^{47}$. Dieser Eindruck verstärkte sich bei seinem Treffen mit Sokolowski am 28. Juni. Der schien „persönlich unglücklich“ über die Entwicklung in Berlin und war offenkundig enttäuscht, daß Clay gegen die Blockade protestierte, aber keinen Vorschlag zur Lösung der Krise unterbreitete ${ }^{48}$. Murphy und Robertson hegten am 1. Juli noch die Hoffnung, Sokolowskis offizielle Antwort auf die westlichen Proteste deute auf ein sowjetisches Einlenken hin ${ }^{49}$. Für die Annahme, die Sowjetunion habe die Rückkehr zu Potsdam und nicht den Bruch erzwingen wollen, spricht, daß der Volksrat der SBZ am 2. Juli vom Kontrollrat einen Volksentscheid zur Wiederherstellung der deutschen Einheit durch einen Friedensvertrag und eine gesamtdeutsche Regierung forderte ${ }^{50}$. Der an den Kontrollrat gerichtete Appell machte nur Sinn, unabhängig von allen Propagandaabsichten, wenn man von der Fortexistenz der Vier-Mächte-Verwaltung und damit der Präsenz der Westalliierten in Berlin ausging, obwohl das „Volksbegehren“ in der SBZ bereits am 23. April bzw. 5. Mai angelaufen war. Die Tägliche Rundschau druckte den Brief und den Gesetzentwurf am 9. Juli auf der Titelseite ab. Noch immer setzten SED und SMAD auf die Volkskongreß-Bewegung, deren Erfolgschancen im Kampf für „Einheit D[eutschlands] u. gerechten Frieden gegen den Marshallplan u. Weststaat" weiterhin optimistisch bewertet wurden ${ }^{51}$.

Zugleich deuteten der endgültige Auszug aus der Berliner Kommandantur am 1. Juli und die explizite Verknüpfung von Berlin-Blockade und „Londoner Empfehlungen" durch Sokolowski am 3. Juli darauf hin, daß die Sowjetunion sich zu diesem Zeitpunkt (aber eben erst jetzt) entschloß, die Blockade von einer geld- und handelspolitischen Abwehrmaßnahme und einer Drohgebärde zur Machtprobe eskalieren zu lassen $^{52}$. Die Lage in und um Berlin entwickelte ihre Eigengesetzlichkeit, die die Sowjets zu einer beständigen Ausweitung ihrer Ziele veranlaßte: Ging es zunächst um

16 CP, S. 697 (K. Royall, 28. 6. 1948). Bemerkenswert der „inoffizielle“ Versuchsballon eines Offiziers aus der Umgebung Sokolowskis, ob man nicht zum Status quo ante vom Juni 1945 zurückkehren solle durch den Rücktausch der Westsektoren Berlins gegen Thüringen und Sachsen. FRUS, 1948/ II, S. 915.

${ }^{47}$ CP, 727. FRUS, 1948/II, S. 947, 1000.

48 NA, RG 59, 740.00119 Control(Germany)/6-2548, /6-2848 und /7-548; RG 59, 800.00 Summaries/ 6-2948. CP, S. 710. Das genaue Gegenteil über Stimmung und Verhalten Sokolowskis in: Clay, Entscheidung, S. 406.

49 FRUS, 1948/II, S. 932. Clay, allerdings in Kenntnis des offiziellen Auszugs der Sowjets aus der Kommandantur am gleichen Tag, war skeptischer. CP, S. 715.

so Tägliche Rundschau, 3. und 9. 7. 1948.

51 Badstübner/Loth, Pieck, S. 230 (5.6. 1948; Hervorhebung im Original). Eine Aufzeichnung Piecks aus diesen Tagen lautet: „Londoner [Sechs-Mächte-?] Konferenz hat Fragen/von denen nicht abkommen/Regierung-Friedensvertrag.“ „Punkt war nicht Reparationen, sondern nächster Punkt/Zentralregierung." Aufschlußreicher dann: "Konsultativrat von oben/Kontrollrat geblieben/Volkskongre $\beta$ von unten.“ „4 Teile - einheitliches Deutschland/nur/solange Potsdamer Beschlüsse - sonst andernorts/Stützpunkte." Eine weitere Aufzeichnung verdeutlicht das Festhalten an der Strategie von 1946: „Wendung an Alliierte - deutscher Konsultativ-Rat als Vorstufe von deutscher Zentralverwaltung“, ohne den Kontrollrat völlig auszuschalten: „Wenn K.R. dann Mitwirkung des Ausgleichs der Meinungen - Gefahr einseitige Festlegungen vermeiden - Irredenta-Gefabr - nat. Hetze." SAPMO, ZPA, Nl 36/739, Bl. 20, 22 (Hervorhebung im Original).

52 Am gleichen Tag befahl die SMAD die Aufstellung von Verbänden kasernierter Polizeibereitschaften, die über die Aufgabe des Schutzes der Zonengrenze hinaus zum Nukleus (para-)militärischer Streitkräfte wurden. Wettig, Entmilitarisierung, S. 221-25. 
das Erzwingen einer Vier-Mächte-Regelung, so gab die vorübergehende Abschottung der SBZ gegen die westliche Währungsreform die Gelegenheit zur Totalblockade; deren Anfangserfolge, die die Franzosen, aber auch die Briten offenkundig erheblich verunsicherten, verleiteten schließlich dazu, die Forderung nach Aufgabe der Staatsgründung in den Westzonen zu erheben. Aus ihrer hilflosen Defensive gegenüber der entschlossenen Politik der Westmächte suchte die Sowjetunion die gesamtdeutsche Initiative zurückzugewinnen. Sollte sie die Gründung eines westdeutschen Staates nicht verhindern können, so wollte sie den Westmächten in Berlin wenigstens eine Niederlage beibringen, den neuen Weststaat diskreditieren, um so für ihre gesamtdeutsche Propaganda neue Resonanz zu gewinnen.

Gleichwohl hielten sich die Sowjets - verunsichert durch den Erfolg der Luftbrücke $^{53}$ und die unerwartete Widerstandsbereitschaft der Westberliner Bevölkerung - eine Hintertüre offen, solange in Moskau die westlichen Botschafter mit Stalin und Molotow über eine Berlin-Lösung verhandelten ${ }^{54}$. Das dort unterbreitete Angebot der Westmächte, die Kommandantur solle die Einzelheiten der Währungsproblematik aushandeln, implizierte für Clay die Reaktivierung des Kontrollrats. „Ich vermute, daß die Währungsverhandlungen automatisch die Kommandantur wiederbeleben werden und daß die Wiederbelebung im Kontrollrat folgen wird, wenn sich Stoff für Verhandlungen ergibt. ${ }^{\text {"55 }}$ Wieder nutzte die Sowjetunion die Chance nicht, wenn es ihr noch um eine solche Lösung gegangen sein sollte. In ihrer Note vom 14. Juli verlangte sie einerseits, mögliche Verhandlungen dürften sich nicht auf Berlin beschränken, sondern müßten die gesamte Frage der Vier-Mächte-Kontrolle in Deutschland zum Gegenstand haben; andererseits wiederholte sie ihren Rechtsstandpunkt, infolge der Außerkraftsetzung der alliierten Vereinbarungen über die Vier-Mächte-Kontrolle seitens der Westmächte habe nicht nur der Kontrollrat seine Tätigkeit „eingestellt“, sondern sei auch „die rechtliche Grundlage für ihre Teilnahme an der Verwaltung von Berlin ebenfalls unterminiert worden“, das „ein Teil“ der SBZ sei. Während Stalin in den Moskauer Verhandlungen sich mündlich bereit erklärte, gegen Zugeständnisse in der Frage des Weststaats eine Vier-Mächte-Kontrolle der Berliner Währung zu akzeptieren $^{56}$, nahm in Berlin die schrittweise Spaltung des Magistrats, der Stadt und der VierMächte-Verwaltung ihren Lauf: Auf Anweisung der SMAD waren um den 10. August Polizei, Geld, Kommunikation, Post und dann auch die Ernährung im Ostsektor abgetrennt worden. Durch die Blockade der städtischen Konten beim Berliner Stadtkontor geriet der Magistrat an den Rand der Zahlungsunfähigkeit ${ }^{57}$. Trotz aller Fortschritte in den Moskauer Verhandlungen kam es zu keinerlei Entspannung in Berlin; vielmehr setzten die Sowjets am 13. August ein weiteres Signal: Der sowjetische

53 AO, Berlin/3271/8/3033 (CCFA, 5. 7. 1948, unter Berufung auf deutsche Quellen aus dem Umfeld der SMAD).

54 FRUS, 1948/II, S. 995 ff., 1034, 1073. Die Verhandlungen im Kontrollratsgebäude in Berlin ebenda, S. $1099 \mathrm{ff}$. Zu inoffiziellen Verhandlungen der vier alliierten Vertreter im Finanzkomitee der Kommandantur mit dem Magistrat Anfang Juli über die Berliner Währungsverhältnisse vgl. ebenda, S. 958 f. CP, S. 796, 798-843 passim.

55 CP, S. 751, 765, 767, 781 .

${ }^{56}$ FRUS, 1948/II, S. 960 ff., Zitat S. 963. In den Moskauer Verhandlungen steuerte Stalin nach dem Eindruck des amerikanischen Botschafters auf eine Deutschlandkonferenz zu. Stalin nannte als Punkte für Vier-Mächte-Verhandlungen: 1. Reparationen, 2. Entmilitarisierung, 3. Bildung einer deutschen Regierung, 4. Friedensvertrag, 5. Ruhrkontrolle; ebenda, S. 1002-06, 1069.

57 AO, Berlin/3271/8/3033. FRUS, 1948/II, S. 1038. 
Stadtkommandant zog die Wache an der Alliierten Kommandantur zurück, ließ die Fahne einholen und die Akten entfernen ${ }^{58}$. Zwar wurden die Verhandlungen über Währungsreform und Berlin, auf die sich die vier Regierungen schließlich in Moskau geeinigt hatten, von den vier Militärgouverneuren in Deutschland geführt; das Protokoll achtete jedoch peinlich darauf, daß diese sich als Militärgouverneure, aber nicht als Mitglieder des Kontrollrats trafen. Dementsprechend war in den Verhandlungen auch keine Rede mehr von Kontrollrat oder Kommandantur, sondern man sprach sehr bedacht nur noch von Ad-hoc-Vier-Mächte-Kontrollgremien bei den relevanten Berliner Organen und Verwaltungen, um den Vier-Mächte-Status und damit die alliierten Rechte zu wahren, ohne ernsthaft eine gemeinsame Verwaltung anzustreben während das Alliierte Sekretariat des Kontrollrats noch immer Akten aufarbeitete ${ }^{59}$.

\section{Rückkehr zum Kontrollrat? 1949-1990. Ein Epilog}

Anders als im Falle der Kommandantur, die gemäß Kontrollabkommen ein Unterorgan der Kontrollbehörde war, gab es keinen formellen Rückzug der Sowjetunion aus dem Kontrollrat selbst. Ein solcher Schritt wäre nicht ohne Folgen für die völkerrechtliche Grundlage der eigenen Besatzungsrechte geblieben. Die Sowjetunion versuchte im Gegenteil, ihre Rechtsposition weiter zu differenzieren, um ihren Anspruch bzw. die westliche Verpflichtung auf eine gemeinsame Verantwortung für ganz Deutschland nicht in Frage zu stellen oder erlöschen zu lassen. Der Kontrollrat „bestehe nicht mehr“, sagte Sokolowski am 7. September 1948 seinen westlichen Kollegen; doch „wenn die deutsche Einheit wiederhergestellt wird“, so relativierte er diese apodiktische Aussage eher beiläufig, werde auch der Kontrollrat „wieder arbeiten“60. Die SED-Führung hielt es im Mai 1949 nicht für ausgeschlossen, daß auf der Pariser Außenministerkonferenz die „Wiederaufnahme der Arbeit des Kontrollrats" und der Berliner Kommandantur als Vorlauf für eine Friedenskonferenz und einen Friedensvertrag beschlossen werde und daß beide Organe auch nach einem Friedensvertrag weiter bestünden ${ }^{61}$. In der Tat zeigte die Sowjetunion auf der Pariser Außenministerkonferenz den „starken Wunsch“ nach „Wiederherstellung“ des Kontrollrats, um ihren Fehler zu korrigieren, durch den Auszug am 20. März 1948 die Gründung eines Weststaates nicht verhindert, sondern im Gegenteil beschleunigt zu haben. Sie war aber nur in nachgeordneten Punkten zu einer Revision der alten Kontrollratskonstruktion bereit, sondern drängte gar noch auf eine Verschärfung des Vetorechts ${ }^{62}$; möglicherweise hing sie noch immer der Illusion nach, für eine solche Lösung die Unterstützung der Deutschen gewinnen zu können, sofern nur die nationale Einheit

58 SBZ von A-Z, 1945-1954, S. 83. Keiderling, Kommandantur, S. 609.

59 AMAE, Eu(1944-1960)Allemagne/775, Bl. 2.

60 CP, S. 840.

61 Badstübner/Loth, Pieck, S. 278 (11. 5. 1949; Hervorhebung im Original). Zwar rechnete man bereits am 23. 5. damit, daß die Pariser Konferenz scheitern werde, das Gesamturteil war aber recht positiv; ebenda, S. 283, 288.

62 AMAE, Y 207, Bl. 4, 163 ff., 213; Eu(1944-60)Généralités/137, Bl. 34 ff. FRUS, 1949/III, S. 920, $924,926,1040 \mathrm{f}$. 
gewahrt blieb ${ }^{63}$. Doch seit der Pariser Konferenz von 1949 hatte sie deutschlandpolitisch die Initiative endgültig verloren und hielt in ihrer Hilflosigkeit an einer Kombinationslösung von Kontrollrat und deutschem Verfassungsrat fest, obwohl nach der Gründung der beiden Teilstaaten dafür die Voraussetzungen nicht mehr bestanden ${ }^{64}$.

Diese Schwäche suchten die Westmächte auszunutzen, in der Hoffnung, die Sowjets zu weiteren Zugeständnissen zwingen zu können. Sie lehnten daher alle Lösungen ab, die zur indirekten Wiederherstellung der Vier-Mächte-Kontrolle geführt hätten. Die Anglo-Amerikaner vermuteten, die Sowjetunion wolle den Kontrollrat als Wahrzeichen alliierter Einheit wiederbeleben, um die Voraussetzungen für die Herstellung der deutschen Einheit zu schaffen. Eine solche Wiederbelebung, die über einen bloß formalen modus vivendi hinausging, sei nur sinnvoll, wenn Übereinstimmung über eine einheitliche Deutschlandpolitik bestehe. Solange die Sowjetunion, das war die klare Forderung, ihre Politik nicht änderte, war die Rückkehr zu den alten, nicht arbeitsfähigen, weil durch Veto belasteten Formen nicht akzeptabel ${ }^{65}$. Bei den internen Vorbereitungen für die Pariser Außenministerkonferenz im Mai/Juni 1949 wurde die Rückkehr zu einer Kontrollratslösung von den Westmächten nur noch am Rande diskutiert. Eine solche Rückkehr war bestenfalls als eine Übergangslösung zur Organisation von Wiedervereinigung und Friedensvertrag denkbar, aber auch dann nur in kleinem Maßstab und vor allem ohne Veto. Letztlich waren die USA jedoch an einer Vier-Mächte-Lösung nicht (mehr) interessiert und sprachen sich daher gegen eine „Wiedererrichtung“ von Kontrollrat und Kommandantur aus, auch wenn sie mit der Idee spielten, im Falle einer Einigung den Kontrollrat zugunsten einer (VierMächte-)Hochkommission ,aufzulösen“, damit erneut dessen Existenz rechtlich anerkennend. „Es ist die Auffassung der USA, daß jetzt keine praktikable Lösung für eine neue vierzonale deutsche Regierung vorstellbar ist und daß eine Drei-Zonen-Regierung wenigstens einen Vorteil hat, indem sie weniger Schwierigkeiten bereitet bei der Sicherstellung der Integration in eine neue westeuropäische wirtschaftliche und politische Struktur." ${ }^{\text {"6 }}$ Für London war eine Rückkehr zum Vier-Mächte-Status nur akzeptabel, wenn sich die SBZ den Regelungen in den Westzonen, von der Währungsreform bis zum Besatzungsstatut, unterwarf ${ }^{67}$. Der Kontrollrat war nicht mehr als eine Rechtsfiktion, einerseits als Legitimation gesamtdeutscher Ansprüche, andererseits als Grundlage für das Besatzungsstatut, mit dessen Hilfe gegenüber der Bundesrepublik die Westintegration durchgesetzt werden konnte. Bei der Umsetzung der Pariser Beschlüsse achteten die Westmächte strikt darauf, daß die Stadtkommandanten von Ber-

63 AMAE, Eu(1944-60)Allemagne/950, Bl. 259.

64 AMAE, Eu(1944-60)Allemagne/904, Bl. $134 \mathrm{ff}$.

${ }^{65}$ Kennan dachte im "Program A“ vom 12.11. 1948 an die „effective elimination of the veto by any individual power" und „a new control machinery“; demnach dürften die Deutschen - nach dem Vorbild Osterreichs - alles tun, „which the four powers do not agree unanimously that they should not do“, dadurch einen Einigungszwang definierend, der zugunsten des Westens ausfallen mußte. FRUS, 1948/II, S. $1325 \mathrm{ff}$.

66 NA, RG 59/Bohlen, box 4, folder: Memo, Paris 1949 (13.6. 1949); RG 43/Post-CFM 1949 Meetings, box 314, folder: German Policy Papers, Washington Conference, April 1949 (IV. Proposals, 30. 3. 1949, Punkt 8c). Die USA befürworteten statt dessen eine Regelung nach dem Vorbild der Alliierten Hohen Kommission in der Bundesrepublik, in der ein Mehrheitsentscheid galt; das Appellationsrecht an die Regierungen hatte nur aufschiebende Wirkung. FRUS, 1949/III, S. 897 f. Zur Alliierten Hohen Kommission vgl. ebenda, S. $181 \mathrm{ff}$.

67 AMAE, Y 207, Bl. 255 ff., 274 ff. 
lin offiziell nicht als Kommandantur zusammentraten und daß alle über Berlin hinausgehenden Fragen von den „Leitern der Besatzungsbehörden“ beraten wurden, aber nicht vom „Kontrollrat“ - auch wenn die Verhandlungen im Kontrollratsgebäude stattfanden ${ }^{68}$.

Wenn die sowjetische Taktik auf der Pariser Außenministerkonferenz darauf abgezielt hatte, Frankreich, das im Frühjahr 1948 aus pragmatischen Gründen am längsten am Kontrollrat festgehalten hatte, aus der westlichen Front herauszubrechen, dann war sie gescheitert. Zwar war die Regierung in Paris 1949 nicht abgeneigt, darin traf die Hoffnung der Sowjetunion teilweise zu, eine Zwischenlösung zu suchen, allerdings nur, wenn damit keine Beteiligung der Sowjetunion an der Ruhrkontrolle verbunden war, die deren eigentliches Ziel zu sein schien. Die „Wiederherstellung eines Systems vom Typ Kontrollrat 1946 oder Österreich“ hätte, selbst bei einem nur „negativen“, d. h. nachträglichen Veto wie im Falle Österreichs, „die vollständige Einheitlichkeit in ganz Deutschland" gewährleistet und die Dauer der Besatzung verlängert. Vorteilhafter schien es inzwischen jedoch, sollte die alliierte Kontrolle auch über die Besatzungszeit hinaus langfristig gesichert bleiben, das für die Westzonen ausgehandelte Besatzungsstatut auf die SBZ auszudehnen. Neben dem Vier-Mächte-Kontrollsystem bzw. unterhalb desselben würden die Länder auf Zonenebene zusätzlich kontrolliert, in den drei westlichen Zonen eventuell auch gemeinsam ${ }^{69}$. In einem solchen dualen System, das die SBZ und Osteuropa öffnen sollte, ohne der Sowjetunion Einfluß auf das Ruhrgebiet zu geben, wäre der Kontrollrat nicht mehr als die „Fassade einer Vier-Mächte-Kontrolle in Berlin“ gewesen $^{70}$. Auf ihn konnte notfalls ganz verzichtet werden, sofern mit der internationalen Ruhrbehörde oder dem Militärischen Sicherheitsamt Instrumentarien vorhanden waren, die auch auf rein westdeutscher Ebene im Sinne der französischen Ziele gehandhabt werden konnten ${ }^{71}$. In der Bilanz erschien es vorteilhafter, einen „Kompromiß über Berlin, modus vivendi zwischen den beiden Deutschland und Zeitgewinn" anzustreben, also Deutschland gespalten zu halten, ohne der Sowjetunion propagandistisch und völkerrechtlich in die Hände zu spie$\operatorname{len}^{72}$.

Alle diese Überlegungen erwiesen sich letztlich als Spielmaterial, das in erster Linie dem Sammeln von Argumenten und Gegenargumenten für den Fall einer neuen Vier-Mächte-Konferenz diente. Als um die Jahreswende 1950/51 erneut über die Einberufung einer Vier-Mächte-Konferenz vorverhandelt wurde, rückte der Kontrollrat

68 BA, Z 45 F/OMGUS, 2/92-2/17 (23. 7. 1949).

69 AMAE, Y 207, Bl. 4, 68 ff., 163 ff., 188, 213 ff., 285, 295, 338 ff., 356 ff.; Eu(1944-60)Allemagne/ 1123, Bl. 16 f., 22 ff. Trotz aller Bedenken hinsichtlich der Durchsetzbarkeit scheint Frankreich auch später noch mit der "Wiederherstellung des Quadripartismus in Berlin“, allerdings nach österreichischem Muster, geliebäugelt zu haben. Doch mochte das der tagespolitischen Auseinandersetzung um Schuman- und Pleven-Plan geschuldet sein. Eu(1944-60)Généralités/137, Bl. 33 ff. (4. 1. 1951), 60 ff. (6. 1. 1951); Eu(1944-60)Allemagne/950, Bl. 416 (17. 10. 1955).

70 AMAE, Y 207, Bl. 229.

71 Als „alliierte Ziele“ für die Pariser Konferenz 1949 wurden genannt: 1. Verhinderung eines Scheiterns der Konferenz; 2. „maintenir les contrôles obtenus: occupation prolongée, Ruhr, industries limitées, OMS [Office Militaire de Sécurité], structure politique fédérale“; 3. ökonomische und politische Öffnung der Satellitenstaaten in Osteuropa. In der Übergangszeit sollten die Sicherheitsfragen mit der Sowjetunion über ein „comité de coordination allié“ bzw. durch deren Einbeziehung in das Militärische Sicherheitsamt gemeinsam geregelt werden. AMAE, Y 207, B1. 227 ff. Das Militärische Sicherheitsamt war 1948 von den USA in die Diskussion eingebrach worden. FRUS, 1948/II, S. 101 .

72 AMAE, Y 207, Bl. $191 \mathrm{ff} ., 213 \mathrm{ff}$. 
abermals ins Blickfeld. Doch nach dem Ausbruch des Korea-Krieges und angesichts der Debatte über die Wiederbewaffnung der Bundesrepublik und ihre Einbeziehung in die NATO kam trotz gewisser Probleme, eine gemeinsame Linie zu finden, eine Rückkehr zu Potsdam, Kontrollrat und sowjetischem Veto, die Kirkpatrick als die Konsequenz des Grotewohl-Briefs vom Januar 1951 bezeichnete, für alle drei Westmächte ernsthaft nicht in Frage - und schon gar nicht für Adenauer ${ }^{73}$. Allerdings war man sich in den westlichen Hauptstädten nicht sicher, ob die Sowjets eine Erneuerung des Kontrollrats (mit oder ohne Friedensvertrag) anstrebten oder lieber eine indirekte Vier-Mächte-Kontrolle durch Neutralisierung vorgezogen hätten ${ }^{74}$. Die Sondierungen kamen jedoch über das Stadium von Vorgesprächen vom März bis Juni 1951 nicht hinaus ${ }^{75}$. Aber die Verhinderung einer Rückkehr zum Kontrollrat durfte nicht zur Aufkündigung der alliierten Kriegsvereinbarungen führen, die als Rechtstitel Grundlage für Proteste und Propagandavorstöße gegenüber der jeweils anderen Seite waren $^{76}$. Solange die Sowjetunion das Potsdamer Abkommen und die Erklärung vom 5. Juni 1945 respektierte, waren beide Dokumente „eher ein Schutz als eine Last. Ihre Klauseln wirken sich zu unseren Gunsten aus, denn unser Recht, in Berlin zu sein, leitet sich aus ihnen ab, und die Sowjets können sie nicht heranziehen, um in Westdeutschland Einfluß zu nehmen." ${ }^{\text {"77 }}$ Zudem beruhte die Legitimation der westlichen Vorbehaltsrechte gegenüber der Bundesrepublik auf dieser Grundlage. In Artikel 3 des Besatzungsstatuts behielten sich die Westmächte ausdrücklich das Recht vor, ,auf Anweisung ihrer Regierungen ganz oder zum Teil die Ausübung der vollen Gewalt wiederaufzunehmen, wenn diese Regierungen der Auffassung sind, daß dies für die Sicherheit oder die Erhaltung der demokratischen Regierung in Deutschland oder in Wahrnehmung der internationalen Verpflichtungen ihrer Regierungen notwendig ist“. Das begründete nicht nur ein Recht zur Intervention in die bundesdeutsche Innenpolitik, sondern eröffnete auch die Möglichkeit, sich über den Kopf der Bundesregierung hinweg, die lediglich zu informieren war, mit der Sowjetunion über Deutschland als Ganzes zu arrangieren.

Je mehr an Souveränitätsrechten den beiden Teilstaaten übertragen und der Kontrollrat zur rechtlichen und politischen Fiktion wurde, um so drängender ergab sich

73 FRUS, 1950/IV, S. 673. FRUS, 1951/III, S. 1339. Zum Jahreswechsel 1950/51 unternahm Frankreich einen zögernden Versuch, die Neuregelung der Besatzungsrechte auf Vertragsbasis mit dem Argument zu umgehen, man sei durch Yalta und Potsdam gegenüber der Sowjetunion gebunden; bei einer Aufkündigung dieser Bindungen würden Vier-Mächte-Verhandlungen unmöglich gemacht. FRUS, 1950/IV, S. 808 (Schuman, 19. 12. 1950). FRUS, 1951/III, S. 1446.

74 Offenbar hatte die Sowjetunion dazu selbst keine klare Meinung. Gegenüber Vertretern der SED/ DDR bezeichnete Stalin am 1.4. 1952 eine Vier-Mächte-Konferenz als mögliche Weiterung seiner Noten-Offensive. Otto, Deutschlandnote, S. 382, 386. FRUS, 1951/III, S. 1992 f.

75 FRUS, 1951/III, S. 1086-1162. Auf der Konferenz wurde der Kontrollrat von keiner Seite zur Sprache gebracht. Die UdSSR zeigte vorrangig Interesse an der Wiederbelebung des Außenministerrats; ebenda, S. 1051, 1099.

76 Die Westmächte begründeten ihren Protest gegen die Errichtung der (kasernierten) Volkspolizei im Mai 1950 mit der Proklamation Nr. 2 vom 20. 9. 1945 und dem Kontrollratsgesetz Nr. 34 vom 20.8. 1946. FRUS, 1950/IV, S. 948 ff. Ruhm von Oppen, Documents, S. $493 \mathrm{ff}$. Die Sowjetunion hielt dem am 20. 10. 1950 entgegen, diese stehe im Einklang mit der Direktive Nr. 15 vom 6. 11. 1945. AMAE, Eu (1944-1960)Généralités/136, Bl. 5.

77 AMAE, Eu(1944-60)Généralités/137, Bl. 262 ff., 295. FRUS, 1951/III, S. 1446 f. Die westlichen Stadtkommandanten warnten 1951, „to tamper with the legal authority reposing in the Allied Control Council, from which the authority of the Allied Kommandantura depends, as long as the Control Council still theoretically exists“. FRUS, 1951/III, S. 1923. 
für die Alliierten und erst recht für die beiden deutschen Regierungen die Notwendigkeit, die Kontrollratsgesetzgebung und die Vorbehaltsrechte auf eine völkerrechtliche Vertragsbasis umzustellen ${ }^{78}$. Bei den Verhandlungen über den Generalvertrag im April 1952 zwischen der Bundesregierung und den drei Westmächten ging es Adenauer in erster Linie darum, die Proklamation Nr. 2 vom 20. September 1945 aufzuweichen, die die Übernahme der obersten Gewalt durch die Alliierten vom 5. Juni 1945 durch die Deutschland zusätzlich auferlegten Bedingungen ergänzte. Doch sein Versuch, der Bundesrepublik das Recht zu sichern, ,alle Kontrollratsvorschriften auBer Anwendung [zu] setzen [...], die nicht die [alliierten] Vorbehaltsrechte berühren“, war nur teilweise erfolgreich. Die Proklamation Nr. 2, die fast alle Bereiche der Gesetzgebung erfaßte, wurde auf Verlangen der Bundesregierung von den Westmächten für das Territorium der Bundesrepublik „außer Wirksamkeit gesetzt“; aufheben, so die übereinstimmende Rechtsauffassung noch 1951, könne man sie nur gemeinsam mit der Sowjetunion. In dem Zusammenhang stellte McCloy für die Westmächte ausdrücklich fest, „daß gegenüber den Russen der Kontrollrat auch heute noch bestehe ${ }^{\text {“79 }}$. Derartige Äußerungen bestärkten Adenauers Potsdam-Komplex. Sein Mißtrauen wuchs, als die Sowjetunion in der zweiten Stalin-Note vom 9. April 1952 zur Vorbereitung des Friedensvertrags eine Kommission der vier Mächte, „die Besatzungsfunktionen in Deutschland erfüllen“, vorschlug, um die Voraussetzungen für freie Wahlen zu überprüfen. Eine solche Kommission wurde von den USA abgelehnt,

78 Der Überleitungsvertrag mit den Westalliierten von 1952 sah vor, daß Kontrollratsgesetze von deutscher Seite weder aufgehoben noch geändert werden durften ohne „Konsultation“ mit den Besatzungsmächten. In den Neuverhandlungen, die infolge des Scheiterns der EVG möglich wurden, blieben diese Passagen unverändert, doch stand der Überleitungsvertrag durch das Pariser Protokoll vom 23. 10. 1954 „,näher beim Grundgesetz", indem der deutsche Gesetzgeber seit dem 5. 5. 1955 Rechtsvorschriften der Besatzungsbehörden aufheben durfte. Das Bundesverfassungsgericht sah daher 1963 seine „Prüfungskompetenz" als gegeben an und setzte dem Gesetzgeber Fristen, innerhalb derer alliiertes Recht, soweit es dem Grundgesetz entgegenstand, anzupassen war. Münchner Kommentar zum Bürgerlichen Gesetzbuch, hrsg. von Kurt Rebmann und Franz Jürgen Säcker, München 1989, Bd. 5, 1, S. 1599 ff. Entscheidungen des Bundesverfassungsgerichts, Bd. 15, Tübingen 1964, S. 342 ff. Da die in Art. 117, Abs. 1 GG für das Gleichheitsprinzip zwischen Mann und Frau nach Art. 3, Abs. 2 GG vorgesehene Übergangsfrist nicht eingehalten wurde (Kabinettsprotokolle, Bd. 5: 1952, S. 407), sorgte das Bundesverfassungsgericht für eine Teilanpassung; weitere Teile des Ehegesetzes wurden 1976 durch Bundesgesetz in das Bürgerliche Gesetzbuch rückgeführt, während die von beiden Novellierungen nicht betroffenen Teile des Kontrollratsgesetzes Nr. 16 geltendes Recht blieben. - In der DDR blieb ein Teil der SMAD-Befehle bis 1954 in Kraft. Mit Auflösung der Sowjetischen Kontrollkommission (SKK) wurden die sowjetischen Vorbehaltsrechte auf völkerrechtliche Vertragsbasis umgestellt. Otto, Deutschlandnote, S. 376.

79 AAPD, Bd. 2, S. 43 ff., 123, 248 f., 262. Betroffen waren auch die Kontrollratsgesetze Nr. 8, 34 und 43 sowie besonders die Entmilitarisierungsvorschriften der Kontrollratsgesetze Nr. 10 (Kriegsverbrecher), 23 (Verbot militärischer Bauten) und 25 (Forschungskontrolle), die als ,weiterhin in Kraft“ angesehen wurden. Die Direktiven Nr. 43 und 47, die den Interzonenverkehr betrafen, seien obsolet, da sie von der Sowjetunion nicht mehr ,respektiert" würden. BA-MA, BW 9/122, Bl. 73. AMAE, Eu(1944-60)Allemagne/1123, B1. 9, 16 f. FRUS, 1950/IV, S. 655. FRUS, 1951/III, S. 997. Das MaxPlanck-Institut für ausländisches Öffentliches Recht und Völkerrecht betrachtete den „Kontrollratsmechanismus“ auch ohne formelle Aufkündigung seitens der Alliierten als „überholt“. „Die Praxis sämtlicher vier Besatzungsmächte ist nach dem Eintritt der Funktionsunfähigkeit des Kontrollrats davon ausgegangen, dass für die Ausserkraftsetzung von Bestimmungen der Kontrollratsgesetzgebung ein Zusammenwirken der vier Besatzungsmächte nicht erforderlich ist, sondern die Besatzungsmächte in ihren Besatzungszonen selbstständig [sic] handeln können.“ Das habe die Alliierte Hohe Kommission mehrfach praktiziert. Geregelt wurden diese Fragen in Artikel 1 (2) des Überleitungsabkommens zum Vertrag über die Beziehungen zwischen der Bundesrepublik und den drei Westmächten vom 26.5. 1952, inkl. eines Briefwechsels, der die unterschiedlichen Standpunkte enthielt. BA-MA, BW 9/220, Bl. 140 ff. Jaenicke, Abbau. Bonner Vertrag, S. 155 ff., 167 ff. 
da sie „als ein Schritt zur Wiedererrichtung der Vier-Mächte-Kontrolle in Deutschland interpretiert werden könnte“; das Potsdamer Abkommen sei nur für die „erste Kontrollperiode“ gedacht gewesen, zu der es kein Zurück mehr geben könne. Auch die Briten verwarfen den Vorschlag mit einem noch deutlicheren Bezug auf den Kontrollrat; „die Erfahrungen in der Phase der Vier-Mächte-Kontrolle Deutschlands legen nahe, daß sie [die Kommission] nicht in der Lage sein würde, nützliche Beschlüsse zu erzielen." Der französische Außenminister Schuman wollte ebenfalls eine Rückkehr zur Vier-Mächte-Kontrolle verhindern, um der Sowjetunion den Rekurs auf eine gesamtdeutsche Verzögerungstaktik zu verweigern - auch wenn man nicht davor zurückscheute, durch Vier-Mächte-Gespräche in Berlin Adenauer zu drohen, „daß es die Alternative gebe, zum Kontrollrats-Verfahren zurückzukehren, wenn die Deutschen sich weigern, den [Besatzungs-]Verträgen zuzustimmen “80. Insofern war Adenauers Verdacht nicht unbegründet, Franzosen und Briten wollten sich die Rückkehr zur Vier-Mächte-Kontrolle formaljuristisch offenhalten. Unterstützt von den USA, bestand er erfolgreich auf einer Formulierung, die für den Fall der Wiedervereinigung eine Rückkehr zum Kontrollratsregime ausschließen sollte ${ }^{81}$.

Diese Vorsicht schien sich als berechtigt zu erweisen. Nachdem Churchill eine Vier-Mächte-Konferenz angeregt hatte, die von Frankreich bald als unabdingbare Voraussetzung für die Ratifizierung der EVG verlangt wurde, dementierte die Sowjetunion am 23. August 1952, daß sie das Vier-Mächte-Kontrollsystem wiederbeleben wolle ${ }^{82}$. In ihren Vorstößen des Jahres 1953 mehrten sich jedoch die Angebote, zum Potsdamer Abkommen und zur Gesamtverantwortung der vier Mächte gegenüber einer provisorischen gesamtdeutschen Regierung in der Vorlaufphase zu einem Friedensvertrag zurückzukehren. Am 29. Mai 1953 schlug Semjonow den Hohen Kommissaren der Westmächte die (Wieder-)Einberufung des Kontrollrats vor, „der rechtlich niemals abgeschafft worden ist“, sondern lediglich nicht mehr zusammengetreten sei $^{83}$. Der 17. Juni 1953 machte solche Überlegungen obsolet. Die Westmächte, die sich in der Offensive sahen, waren nicht mehr bereit, hinter die Konstruktion der Hohen Kommission bzw. des Grundlagenvertrags zurückzugehen und „lehnten eine Rückkehr zu diesem überholten System der Vier-Mächte-Kontrolle kategorisch ab“: Während des Wiedervereinigungsprozesses sollten die vier Mächte die oberste Gewalt zwar weiterhin behalten, aber „keine besondere Kontrolle über die Nationalversammlung oder die provisorische gesamtdeutsche ,Regierung' ausüben; nachdem die gesamtdeutsche Regierung eingesetzt ist, würden die vier Mächte keine größeren Kontrollen ausüben als die, die im Grundlagenvertrag vorgesehen sind, bis zu dem Zeitpunkt, an dem der Friedensvertrag in Kraft tritt" ${ }^{\text {"84 }}$.

Auch nach dem Übergang zur „Zwei-Staaten-Theorie“ gab die Sowjetunion die Möglichkeit einer Rückkehr zu „Potsdam“ nur zögernd auf. In verschiedenen Verträ-

80 FRUS, 1952-54/VII, S. 200, 216, 224 (Zitat), 227, 231, 236, 246 ff., 259, 314. Meyer-Landrut, Frankreich, S. 62, 80. Insofern war mit diesem Notenwechsel keineswegs von allen vier Mächten die Rückkehr zum Kontrollrat endgültig abgelehnt worden, so daß der Kontrollrat hier seine „stillschweigende, vollständige Auflösung“" gefunden habe. Antoni, Potsdamer Abkommen, S. 303.

81 Kabinettsprotokolle der Bundesregierung, Bd. 5 (1952), S. XLIII f., 333.

82 FRUS, 1952-54/VII, S. 294.

83 AMAE, Eu(1944-1960)Allemagne/775, Bl. 4.

${ }^{84}$ FRUS, 1952-54/VII, S. 471 ff. (Reber, 16. 6. 1953), 477 (Dulles, 25. 6. 1953), 481 (Conant, 25. 6. 1953), 735 f. (Fuller an Bowie, 5. 1. 1954). 
gen mit der DDR und Erklärungen hielt sie bis 1955 an dem Prinzip einer andauernden Vier-Mächte-Verantwortung für den Friedensvertrag mit Deutschland fest. Im Umfeld der Berliner Konferenz 1954 häuften sich noch einmal die Signale an Frankreich, ,daß die einzig wirklich sichere Lösung die Rückkehr zu Potsdam und zur wirklichen Vier-Mächte-Kontrolle Deutschlands sei oder, sollte dies scheitern, die gemeinsame Kontrolle durch die Franzosen und die Russen auf der Grundlage einer wiederbelebten französisch-russischen Allianz"85! Die "gemeinsame Verantwortung für die Regelung der deutschen Frage und die Wiedervereinigung Deutschlands“ wurde am 23. Juli 1955 auf der Genfer Konferenz von allen vier Mächten bekräftigt. Aber bereits im selben Jahr begann das allmähliche Abrücken der Sowjetunion von dieser Position, indem sie die Wiedervereinigung zur Sache der Deutschen erklärte, wenngleich im Rahmen eines gesamteuropäischen Systems kollektiver Sicherheit. Beide Ebenen schlossen eine autonome Vier-Mächte-Lösung aus - und damit auch endgültig die Rückkehr zum Kontrollrat. Je verbissener Chruschtschow versuchte, die DDR als eigenständigen Staat aufzuwerten und West-Berlin einen besonderen Status zu verleihen, desto hinderlicher wurden die Rechte der Westmächte, die sich aus dem Potsdamer Abkommen ergaben. Am 10. November 1958 kündigte er das Abkommen als „überlebte Verpflichtung" faktisch auf, da von ihm außer dem besonderen Berlin-Status und dem Recht der vier Siegermächte, den Friedensvertrag mit Deutschland abzuschließen, nichts übrig geblieben $\mathrm{se}^{86}$. Erst 1962 leugnete die Sowjetunion mit der Auflösung des Amts des sowjetischen Stadtkommandanten den Vier-Mächte-Status Berlins formell, wenngleich Chruschtschow 1964 vor der letzten Konsequenz zurückscheute, mit der DDR nicht nur einen Freundschafts-, sondern auch einen einseitigen Friedensvertrag abzuschließen. Angesichts der sowjetischen Distanzierung von Potsdam bekräftigten die Westmächte ihr Festhalten am Kontrollabkommen, das die Sowjetunion nicht einseitig aufkündigen könne, und zwangen Moskau im Laufe der Berlin-Krise zur Anerkennung dieses Rechtsstandpunktes ${ }^{87}$. Auch die Sowjetunion berief sich in der Note an die Bundesregierung vom 21. November 1967 wieder ausdrücklich auf ihre aus dem Potsdamer Abkommen abgeleiteten Rechte ${ }^{88}$. Obwohl die gemeinsame Wahrnehmung der Vier-Mächte-Verantwortung für Deutschland als Ganzes de facto nicht mehr möglich war, wurde der Anspruch de jure und symbolisch von allen vier Mächten übereinstimmend im Berlin-Abkommen von 1971 und in der Erklärung der Vier Mächte vom 9. November 1972 anläßlich des Beitritts der beiden deutschen Staaten zur UNO bekräftigt.

Entgegen ersten sowjetischen Absichten kam 1990 ein formeller Friedensvertrag mit Deutschland nicht zustande, sondern die alliierten „Rechte und Verantwortlichkeiten in bezug auf Berlin und Deutschland als Ganzes" endeten mit dem "Vertrag

85 FRUS, 1952-54/VII, S. 753 (Rodionow). Die Vier-Mächte-Kontrolle sollte darin bestehen, daß in der Übergangszeit 1. „begrenzte Kontingente“ alliierter Truppen in Deutschland stationiert blieben, 2. ein Interventionsrecht beibehalten wurde und 3. „Inspektionsteams, zusammengesetzt aus Vertretern der Vier Mächte“ die Einhaltung der Vereinbarungen überwachten. Das neutrale Gesamtdeutschland würde in ein europäisches Sicherheitssystem eingebunden werden, in dem die USA nur einen Beobachterstatus hätten, ohne daß dadurch ihre besonderen Rechte gegenüber Deutschland bis zum Friedensvertrag aufgehoben werden sollten; ebenda, S. $1189 \mathrm{ff}$. Zu Avancen an Frankreich, aber auch England; ebenda, S. 815, 835, 914. Rupieper, Berliner Außenministerkonferenz.

86 Dokumente zur Deutschlandpolitik, IV. Reihe, Bd. 1,1, S. 17-20.

87 Keesings Archiv der Gegenwart, 1962, S. 10061 . EA, 1962, S. D 443 f.

88 Hacker, Funktion, S. 12 ff., hier S. 15. 
über die abschließende Regelung in bezug auf Deutschland“ vom 12. September 1990, der dem vereinten Deutschland die „volle Souveränität über seine inneren und äußeren Angelegenheiten“ einräumte: „Als Ergebnis werden die entsprechenden, damit zusammenhängenden vierseitigen Vereinbarungen, Beschlüsse und Praktiken beendet

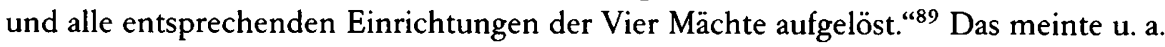
das Zonenabkommen vom 12. September und das Kontrollabkommen vom 14. November 1944; erst jetzt hörten Kontrollrat und Berliner Kommandantur formell auf zu existieren ${ }^{90}$. Angesichts der inzwischen erzielten Bindungen durch bilaterale völkerrechtliche Verträge und den Beitritt zu multilateralen Organisationen war ohnehin kaum noch überschaubar, ob die Rechte der Siegermächte nicht „obsolet" geworden und welche „Restbestandteile“ alliierten Rechts noch gültig und insofern aufzuheben waren, zumal nachdem die „Realteilung“ der obersten Regierungsgewalt in Deutschland zu einer unterschiedlichen Wahrnehmung der Vorbehaltsrechte geführt hatte. Lediglich Status- und Gebietsfragen waren - abgesehen von Berlin - bis zuletzt der Vier-Mächte-Verantwortung unbeeinträchtigt vorbehalten geblieben ${ }^{91}$. Manche Aspekte eines Friedensvertrages, etwa die Beendigung des Kriegszustandes, hatten im Vorgriff Erledigung gefunden; andere, so die deutschen Auslandsguthaben oder die Reparationen, waren uneinheitlich und nicht immer völkerrechtlich verbindlich, $z$. B. gegenüber den kleineren Mächten, geregelt worden ${ }^{92}$. Weitere alliierte Kontroll-, Stationierungs- und Vorbehaltsrechte im Bereich der Bundesrepublik waren frühzeitig in indirektere Formen (NATO-Vertrag, Truppen-Statut) übergeleitet worden ${ }^{93}$ oder wurden durch völkerrechtliche Verpflichtungen des vereinten Deutschland abgelöst, etwa im Hinblick auf die Stationierung von Truppen der vier Mächte.

Die pragmatische Nonchalance, mit der auf die klassischen Formen eines Friedensvertrages verzichtet wurde, dokumentierte einerseits, daß „Potsdam“ obsolet geworden war. Andererseits vollzog sich die deutsche Wiedervereinigung nicht nur im territorialen Rahmen des Kontrollratsgebiets, einschließlich der Saar und ohne die Gebiete östlich von Oder und Neiße, sondern auch in Formen, die in mancherlei Hinsicht den ursprünglichen Planungen für die Konstruktion des Kontrollrats der (westlichen) Alliierten entsprachen: Die Ablösung der alliierten Kontroll- und Vorbehaltsrechte sowie die abschließende Friedensregelung erfolgten durch Einbindung in eine (gesamt)europäische Nachkriegs- und Friedensordnung: durch strukturelle Wirtschaftsverflechtung und institutionelle Integration, überwölbt vom sicherheitspolitischen Dach der KSZE.

89 Bundesgesetzblatt, Teil II, 1990, S. 1317 ff., hier S. 1324 (Artikel 7).

90 Blumenwitz, Vertrag, S. 3047.

91 Rapp, Ende, S. 197 ff. Rauschning, Beendigung, S. 1283 ff. Frowein, Verfassungslage, S. $11 \mathrm{ff} ., 21 \mathrm{ff}$.

92 Das Londoner Schuldenabkommen von 1953 führte seitens der Bundesrepublik Deutschland zur Regelung der Vorkriegsschulden mit 18 Staaten, zwölf weitere traten bei; doch gemäß Überleitungsvertrag vom 26. 5. 1952/23. 10. 1954 wurde die endgültige Regelung der Reparationen einem Friedensvertrag vorbehalten. Auch die Regelung des deutschen Auslandsvermögens wurde im Ủberleitungsvertrag nur teilweise abgeschlossen. Gegenüber mehreren west-, osteuropäischen und neutralen Staaten wurde die Fortgeltung des Kontrollratsgesetzes Nr. 5 ausdrücklich aufrechterhalten; ansonsten wurde auch dieses ,außer Wirksamkeit gesetzt“. Bonner Vertrag, S. $219 \mathrm{ff}$.

${ }^{3}$ FRUS, 1952-54/VII, S. 82 f. 